\title{
Sole metastatic spread from a renal cell carcinoma presenting as a goitre 6 years following renal cell carcinoma
}

\section{Livingstone R, Drummond RS. Department of Diabetes \& Endocrinology, Glasgow Royal Infirmary}

A 68 year old lady with no past medical history was found to have an incidental grade 2, pT1b clear cell carcinoma of the kidney during investigation of back pain with MRI spine. She underwent total nephrectomy and remained well.

Five years later she was demonstrated to have subclinical thyrotoxicosis and multinodular goitre. Antibodies were negative, uptake scan normal and 2 FNA attempts revealed Thy3a.

She had a diagnostic left hemithyroidectomy and pathology showed metastases of renal origin on a background of nodular hyperplasia. There was no other disease, and she has now had completion thyroidectomy.

Pathology was CD10 positive and thyroglobulin negative.
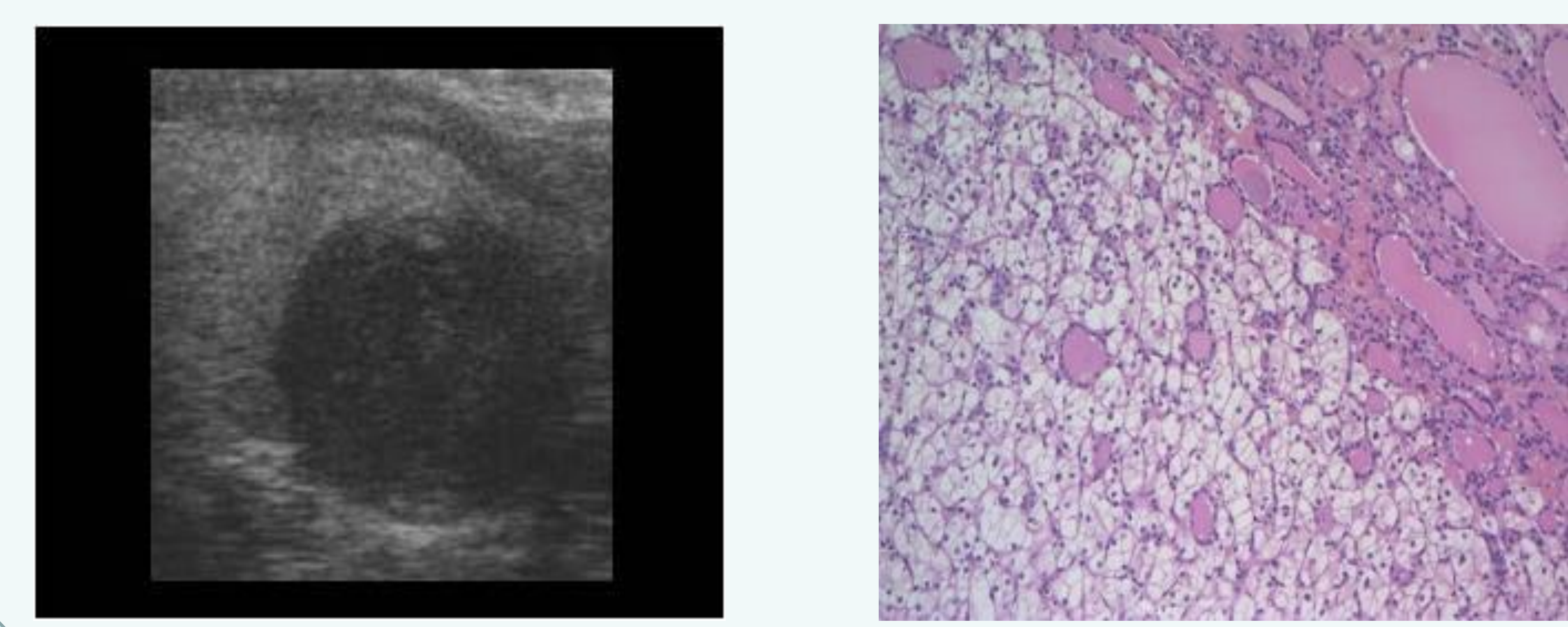

Metastatic disease to the thyroid is rare, accounting for $2-3 \%$ of thyroid malignancy. The most common malignancy to metastasise to thyroid is renal cell carcinoma (48.1\%), followed by colorectal (10.4\%) and lung (8.3\%) (1). Clinically, clear cell renal cell carcinoma (CCRCC) can present with thyroid metastases years or decades later (1). Several studies have shown that thyroid gland abnormalities, including nodular goitre or thyroiditis, are more likely to harbour metastases (2).

Metastatic renal cell carcinoma to the thyroid should be considered in any patient presenting with thyroid mass and past history of renal carcinoma.

References

1. Medas et al. Renal cell carcinoma metastasis to thyroid tumor: a case report and review of the literature. 2013

2. Lee et al. A Case of Metastatic Renal Cell Carcinoma to Thyroid Gland. 2011. 